\title{
Impact of Clinical Presentation on Early Vascular Healing After Bioresorbable Vascular Scaffold Implantation
}

\author{
MORITZ BAQUET, M.D., ${ }^{{ }^{*}}$ CHRISTOPH BRENNER, M.D., ${ }^{2 *}$ MAXIMILIAN WENZLER, ${ }^{1}$ \\ MADELEINE EICKHOFF, M.D., ${ }^{1}$ JOCHHEIM DAVID, M.D., ${ }^{1}$ STEFAN BRUNNER, M.D., ${ }^{1}$ \\ HANS THEISS, M.D., ${ }^{1}$ STEFFEN MASSBERG, M.D., ${ }^{1,3}$ GIULIO GUAGLIUMI, M.D., ${ }^{4}$ \\ and JULINDA MEHILLI, M.D. ${ }^{1,3}$
}

From the ${ }^{1}$ Department of Cardiology, Munich University Clinic, Ludwig-Maximilian University, Munich, Germany; ${ }^{2}$ Department of Internal Medicine III, Medical University of Innsbruck, Innsbruck, Austria; ${ }^{3}$ Munich Heart Alliance at DZHK, Munich, Germany; and

${ }^{4}$ Interventional Cardiology Unit, Azienda Ospedaliera Papa Giovanni XXIII, Bergamo, Italy

\begin{abstract}
Background: Optimal strut coverage and early vascular healing are important factors to reduce the risk of stent thrombosis. Data on early vascular healing with the new bioresorbable vascular scaffolds (BVS) are lacking. Further, healing response after BVS implantation in different clinical presentation has not been fully investigated. Methods and Results: We assessed with optical coherence tomography (OCT) the early vascular response to BVS implantation in 26 consecutive patients presenting with acute coronary syndrome (ACS) or stable angina (SA). Images from 16 BVSs (17,166 struts) in ACS patients and 17 BVSs (23,045 struts) in SA patients were analyzed. The mean implanted BVS diameter and length was $3.1 \pm 0.4 \mathrm{~mm}$ and $20.4 \pm 5.8 \mathrm{~mm}$. At mean $47.6 \pm 6.3$ days, overall 99\% of BVS struts were covered. There were no differences between ACS and SA on the amount of tissue coverage per strut $(0.09 \pm 0.02 \mathrm{~mm}$ vs. $0.09 \pm 0.01 \mathrm{~mm} ; P=0.86$, respectively) and lumen area stenosis $(24.2 \pm 19.3 \% \mathrm{vs}$. $22.3 \pm 22.0 \% ; P=0.78$, respectively). However, a numerically higher proportion of protruding (ACS $1.2 \pm 2.7 \%$; $S A 4.2 \pm 6.5 \% ; P=0.11)$ and malapposed (ACS $0.4 \pm 0.5 \% ; S A 2.4 \pm 5.8 \% ; P=0.18$ ) struts were observed in $S A$ compared to ACS, with trendy better healing score in ACS (1.87 \pm 1.67 vs. $5.28 \pm 7.28, P=0.08)$.

Conclusion: Early after BVS implantation almost complete scaffold strut coverage without any thrombi was observed by OCT, independent by the clinical presentation at index coronary intervention. However, BVS in ACS lesions were associated with easier strut penetration and a trendy better healing score compared with SA. (J Interven Cardiol 2017;30:16-23)
\end{abstract}

\section{Background}

Increasing evidence demonstrate similar efficacy of BVS and newest generation drug-eluting stents (DES) at 1-year follow-up. ${ }^{1-5}$ However, registries as well as randomized trials reported slightly higher rates of thrombosis in BVS compared with DES..$^{1,2,4,5}$ Similar to metallic DES, acute coronary syndrome plays a role

"MB and CB contributed equally to this paper.

Grant sponsor: DZHK and unrestricted grant from Abbott Vascular. Address for reprints: Julinda Mehilli, M.D., F.E.S.C., Munich University Clinic, Ludwig-Maximilians University, Munich Heart Alliance at DZHK, Marchioninistr 15, 81377 Munich. Fax: +49 89 4400 78788; E-mail: julinda.mehilli@med.uni-muenchen.de in the risk of scaffold thrombosis, however procedural aspects such as more demanding size selection with BVS, incomplete lesion preparation with suboptimal scaffold expansion, have been identified to possibly explain these observations. ${ }^{5,6}$ The majority of BVS thrombosis were reported to occur during the first 30 days, which might suggest, due to thicker polymeric struts (around $157 \mu \mathrm{m}$ ), high flow recirculation around struts and delayed endothelialization as an additional substrate for scaffold thrombosis. ${ }^{5,7,8}$ Although in vivo data on early BVS vascular healing (within the first 2 months) are lacking, similar healing pattern between BVS and current generation DES was reported at follow-up later than 6 months after the implantation. ${ }^{9,10}$ Nevertheless, intraluminal masses were more 
frequently observed with BVS (12.9\% of lesions) compared with EES ( $0 \%$ of lesions). ${ }^{9}$ Evidence from OCT-guided BVS implantation studies suggests that both BVS expansion and eccentricity are significantly impacted by plaque composition, morphology, and burden. ${ }^{11}$ Therefore, in the current study we aimed to investigate the in vivo early BVS healing response, assessing the possible impact of clinical presentation at the index PCI.

\section{Methods}

Study Design and Population. We analyzed 26 consecutive patients who underwent OCT examination 6-8 weeks after BVS implantation at the Munich University Clinic. All these patients presenting with multivessel disease were scheduled for elective PCI in a second lesion 6-8 weeks after the index PCI performed with BVS implantation. OCT examination was part of the institutional practice after BVS implantation. All patients' data were prospectively entered into the institutional database, based on a predetermined data set.

OCT Imaging and Analysis. OCT was performed by using a frequency domain Lunawave ${ }^{\circledR}$ system (Terumo ${ }^{\mathbb{R}}$ Medical Corporation, Somerset, $\mathrm{NJ})$. Intracoronary nitroglycerine $(0.2-0.4 \mathrm{mg})$ was administered before imaging the target vessel with the implanted BVS. The Fastview ${ }^{\mathrm{TM}}$ OCT catheter was advanced distally to the BVS segment, and imaging acquisition was obtained during the pullback through a non-occlusive flushing technique.

Qualitative and quantitative OCT imaging analyses were performed off-line by two independent readers, unaware of patient and lesion presentation. An initial screening of image quality suitable to morphometric and strut level analysis was performed. Pullbacks were excluded if more than one third of the total BVS length was not analyzable. Frames were considered not analyzable in case $>25 \%$ of the circumference was not visible due to blood contamination and or presence of artifacts.

Quantitative measurements at cross-sectional level were performed by using Medis QIvus 3.0 software (Medis, Medical Imaging Systems, Leiden, The Netherlands), at $0.25 \mathrm{~mm}$ longitudinal intervals. The most distal and proximal section of the scaffold for quantitative metrics was considered as the first frame with at least $50 \%$ of the entire circumference encircled by BVS struts. The peri-scaffold segments, were identified as the $5 \mathrm{~mm}$ proximally and distally located to the scaffold, analyzed at $1 \mathrm{~mm}$ intervals and used to measure the reference lumen. Reference lumen diameter was calculated as the sum of maximal diameters measured proximally and distally to the scaffold divided by two. In case of multiple BVS implantation, frames with overlapping struts were excluded from analysis. Quantitative and qualitative analysis was done according to IWG-IVOCT Consensus document and the recent BVS-OCT standards by Nakatami et al. ${ }^{12,13}$ The methodology of quantitative OCT analysis is shown in Figure 1. Morphometric analysis was including the lumen area, the scaffold area, the neointimal area, the \% lumen area stenosis and the thickness of polymeric strut coverage. The strut level analysis was performed at each single strut identified as an optically translucent right angular black box framed by light-scattering borders. Thickness of strut coverage was defined as distance between the adluminal surface of the strut and the intersection of the lumen contour along a straight line between the long axis of the strut and the center of the stent. Struts were classified as malapposed if the abluminal strut surface was separated from the vessel wall. Struts were considered uncovered in case of partial or complete absence of tissue coverage. Protrusion was present if less than $50 \%$ of the strut thickness was impacted by neointimal tissue (Fig. 2). Healing score was defined according to Raber and colleagues. ${ }^{14}$

Quantitative Coronary Angiography Analysis. Quantitative coronary angiography (QCA) was analyzed off-line before and after scaffold implantation as well as at 6-8 weeks follow up with paired matched angiographic views, using the Medis QAngio XA 7.3 software (Medis, Medical Imaging Systems). The periscaffold segment $(5 \mathrm{~mm}$ proximal and distal to the scaffold) was used to measure the interpolated reference vessel diameter. The following standard parameters were computed: reference diameter, minimal lumen diameter, \% diameter stenosis, in scaffold and in periscaffold segment, in stent, and in-segment lumen loss.

Statistical Analysis. The population was divided in two groups according to clinical presentation at index PCI. Continuous data are presented as mean (standard deviation). Categorical data are presented as counts or proportions (\%). Data distribution was tested for normality using the Kolmogorov-Smirnov test for goodness of fit. Differences between groups were checked for significance using Student's t-test or Wilcoxon rank sum test (continuous data) or the 


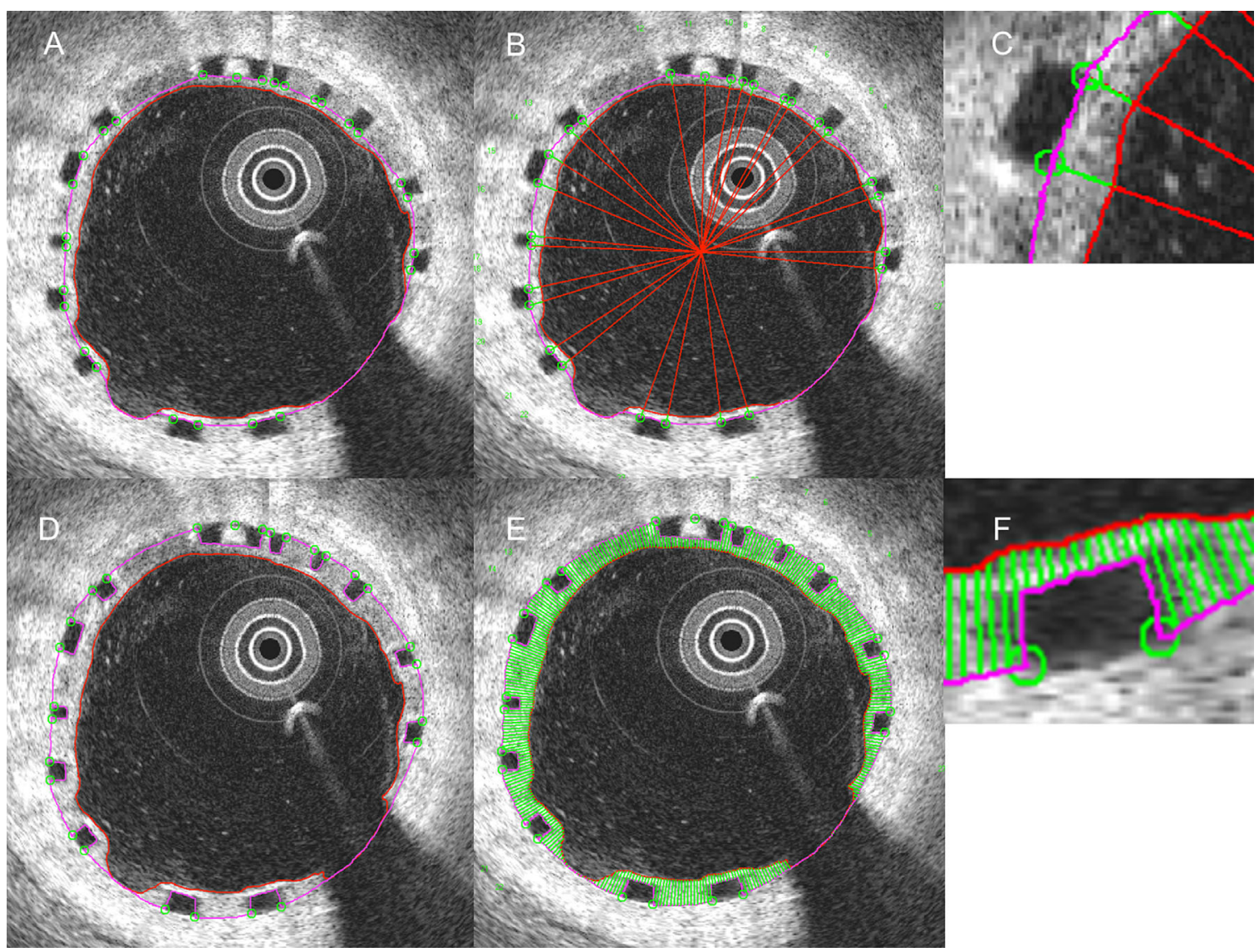

Figure 1. Quantitative OCT analysis methodology. Panels (A, B, and C) demonstrate the quantitative measurement of the tissue thickness per strut. The red line depicts the lumen area, the purple line the adluminal surface of the BVS struts; the green line (C) is the equivalent of tissue thickness per strut, measured in two points per strut. Panels (D, E, and F) shows the quantitative assesement of the neointimal area per frame. The red line depicts the lumen area, the purple line the stent lumen; the green hachured area shows the neointimal area.

chi-square or Fisher's exact test where the expected cell value was $<5$ (categorical variables). A two-tailed $\mathrm{P}$-value of $<0.05$ was considered to indicate statistical significance. Statistical software R-Statistics, (version 3.1.0) was used for analysis.

\section{Results}

Clinical Baseline Characteristics. A total of 26 patients-12 presenting with ACS and 14 with SAwho underwent implantation of at least one BVS (Absorb Version 1.1, Abbott Vascular, Santa Clara, CA) were considered for this analysis. Mean age of the overall population was $65 \pm 9.8$ years, $88.5 \%$ of the patients were men, one third presented with diabetes mellitus and $92 \%$ had multivessel CAD without significant differences between ACS and SA groups (Table 1).

During index PCI in total 33 BVSs were implanted: 16 in ACS patients and 17 in SA patients. Mean diameter and length of implanted BVS was $3.1 \pm 0.4 \mathrm{~mm}$ and $20.4 \pm 5.8 \mathrm{~mm}$, respectively, without differences among ACS and SA patients (Table 1).

Angiographic and OCT Follow Up. Angiographic follow-up was performed at $47.6 \pm 6.3$ days (ACS group $49.7 \pm 7.7$ days and SA group $45.5 \pm 4.2$ days; $\mathrm{P}=0.13$ ). No differences regarding QCA measurements were observed between both groups (Table 2).

The analysis of OCT images was done on strut, cross section and scaffold level. In mean $84.2 \pm 22.7$ cross sections per scaffold (ACS: $84.1 \pm 20.8$; SA: $84.4 \pm 25.0 ; \mathrm{P}=0.97)$ and $1643 \pm 461$ struts per scaffold (ACS: $1640 \pm 386$; SA: $1647 \pm 536 ; \mathrm{P}=096$ ) were 

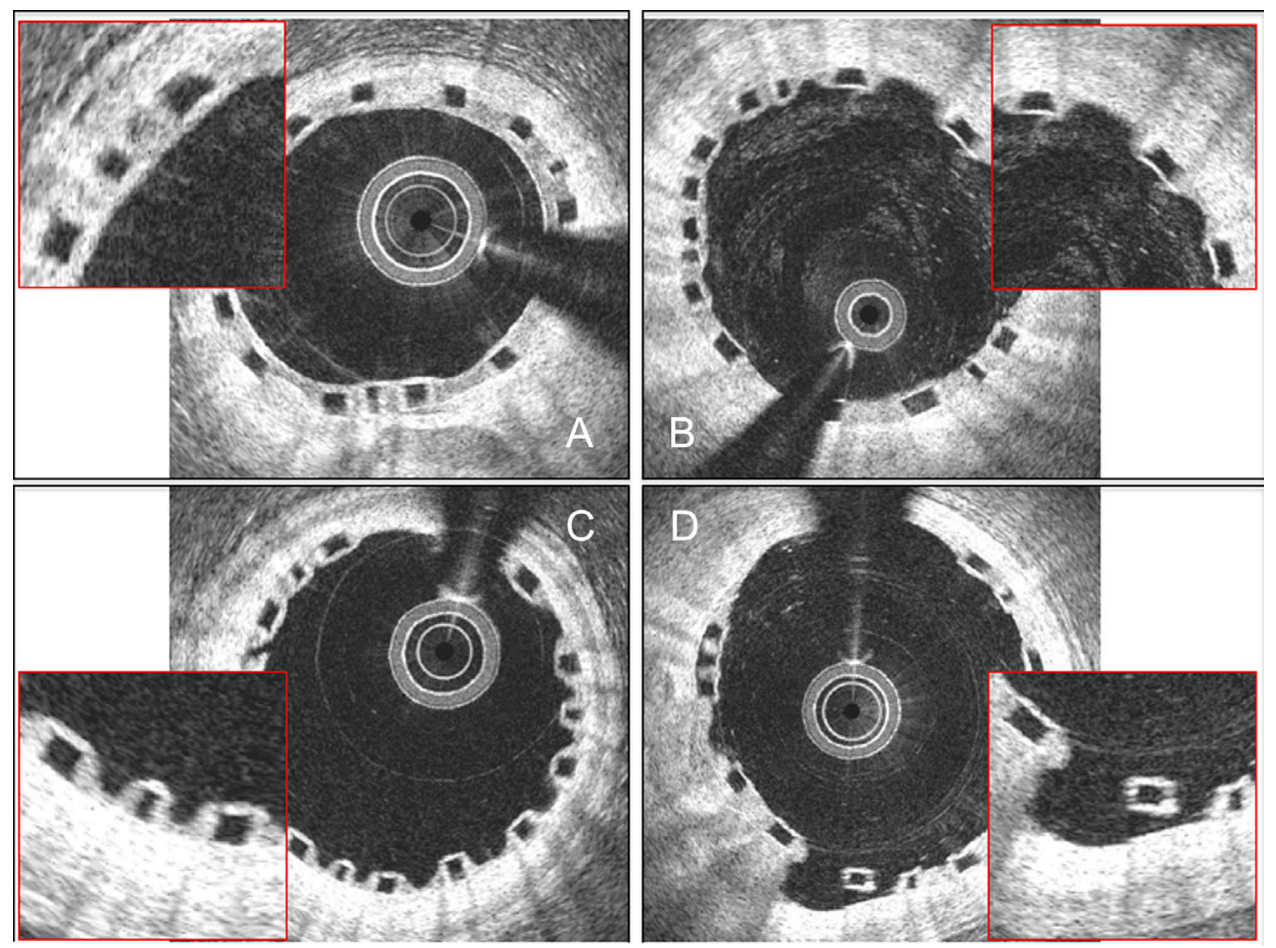

Figure 2. Qualitative OCT analysis methodology. (A) Covered scaffold struts; (B) uncovered struts, no neointimal tissue was observable apon the adluminal surface; $(\mathrm{C})$ protruding struts which extend into the vessel lumen, less than $50 \%$ of the strut is embedded in neointimal tissue; (D) Malapposed strut, the abluminal surface of the scaffold strut is not apposed to the vessel wall.

analyzed. OCT analysis results are shown in Table 3. To highlight, $99 \%$ of the BVS struts were covered without any difference among ACS and SA patients, Figure 3. Qualitative OCT analysis revealed a numerically higher amount of malapposed $(\mathrm{P}=0.1)$ and protruding $(\mathrm{P}=0.06)$ struts, as well as a greater neointimal healing score $(\mathrm{P}=0.08)$ in the SA patients compared to the ACS patients (Fig. 3).

Quantitative OCT analysis showed no differences in terms of tissue coverage per strut and mean neointimal area per cross section early BVS implantation between the ACS and SA groups. Percentages of lumen area stenosis and lumen diameter stenosis were low in both groups at 6-8 weeks after BVS implantation and did not differ significantly (Table 3 ).

\section{Discussion}

This is the first study investigating the early vascular healing after BVS implantation and the impact of clinical presentation on it. The main findings are: (i) at 47 days after BVS implantation vascular healing of the stented wall was nearly complete; (ii) BVS implantation in setting of SA and ACS resulted in similar outcomes regarding amount of neointimal tissue; (iii) proportion of malapposed and protruding scaffold struts was, however, numerically lower after BVS implantation in the setting of ACS.

Bioresorbable scaffold technology was rapidly embraced by interventional community due to its potential of temporary mechanical support of the treated vessel and the prospective of vascular wall healing. The recently published randomized trials demonstrated comparable efficacy and safety of the Absorb BVS with the standard-bearer EES in relatively selected patient and lesion subsets. ${ }^{1,3,4,8}$

However, an increase of scaffold thrombosis was observed particularly in registry and randomized studies enrolling a broader spectrum of patients and lesions ${ }^{4,5,15,16}$ Inaccurate lesion preparation, inadequate BVS size selection or treatments of calcified lesions have been already identified to explain this observation. ${ }^{5,17-19}$ On the other hand, the fact that about $70 \%$ of scaffold thrombosis occur during the first 30 days, might suggest delayed endothelialization of 
BAQUET, ET AL.

Table 1. Clinical and Procedural Baseline Characteristics

\begin{tabular}{|c|c|c|c|c|}
\hline & All $(n=26)$ & $\operatorname{ACS}(n=12)$ & SA $(n=14)$ & P-Value \\
\hline Age, yrs & $65 \pm 9.8$ & $63.6 \pm 9.6$ & $67 \pm 9.9$ & 0.38 \\
\hline Male & $23(88.5)$ & $12(100.0)$ & $11(78.6)$ & 0.28 \\
\hline Hypertension & $23(88.5)$ & $10(83.3)$ & $13(92.9)$ & 0.89 \\
\hline Hyperlipidemia & $7(26.9)$ & $4(33.3)$ & $3(21.4)$ & 0.51 \\
\hline Diabetes & $8(30.8)$ & $5(41.7)$ & $3(21.4)$ & 0.49 \\
\hline Smoker & 7 (26.9) & $4(33.3)$ & $3(21.4)$ & 0.75 \\
\hline NYHA class $\geq 2$ & $5(19.2)$ & $2(16.7)$ & $3(21.4)$ & $>0.99$ \\
\hline Chronic kidney disease & $4(15.4)$ & $0(0.0)$ & $4(28.6)$ & 0.14 \\
\hline History of MI & 7 (26.9) & $4(33.3)$ & $3(21.4)$ & 0.81 \\
\hline History of PCI & $9(34.6)$ & $4(33.3)$ & $5(35.7)$ & $>0.99$ \\
\hline History of CABG & $9(34.6)$ & $4(33.3)$ & $5(35.7)$ & $>0.99$ \\
\hline $\mathrm{LVEF}<50 \%$ & $9(34.6)$ & $5(41.7)$ & $4(28.69$ & 0.85 \\
\hline Extension of CAD & & & & 0.07 \\
\hline Single vessel & $2(7.7)$ & $0(0.0)$ & $2(14.3)$ & \\
\hline Two vessel & $11(42.3)$ & $8(66.7)$ & $3(21.4)$ & \\
\hline Three vessel & $13(50.0)$ & $4(33.3)$ & $9(64.3)$ & \\
\hline TIMI flow $<3$ before PCI & $9(34.6)$ & $7(58.3)$ & $2(14.3)$ & 0.05 \\
\hline TIMI flow $<3$ after PCI & $1(3.8)$ & $0(0.0)$ & $1(7.1)$ & $>0.99$ \\
\hline AHA/ACC class & & & & 0.82 \\
\hline A & $1(3.8)$ & $0(0.0)$ & $1(7.1)$ & \\
\hline B1 & $8(30.8)$ & $4(33.3)$ & $4(28.6)$ & \\
\hline B2 & $11(42.3)$ & $6(50.0)$ & $5(35.7)$ & \\
\hline $\mathrm{C}$ & $6(23.1)$ & $2(16.7)$ & $6(28.6)$ & \\
\hline Implanted BVS size (mm) & $3.1 \pm 0.4$ & $3.2 \pm 0.4$ & $3.1 \pm 0.4$ & 0.76 \\
\hline Implanted BVS length (mm) & $20.4 \pm 5.8$ & $20 \pm 6$ & $20.8 \pm 5.8$ & 0.69 \\
\hline
\end{tabular}

Values are mean $\pm \mathrm{SD}$ or $\mathrm{n}(\%)$. AMI, acute myocardial infarction; BVS, bioresorbable vascular scaffold; PCI, percutaneous coronary intervention; CABG, coronary artery bypass graft; NYHA, New York Heart Association; LVEF, left ventricular ejection fraction; TIMI, Thrombolysis In Myocardial Infarction; CAD, coronary artery disease; AHA, American Heart Association; ACC, Amercican College of Cardiology.

BVS thick struts $(157 \mu \mathrm{m})$ as an additional substrate for scaffold thrombosis. ${ }^{5}$ Against this background, our findings are of great clinical relevance. Less than $1 \%$ of scaffold struts were uncovered in our study, despite the fact that the OCT examination was performed in about 7 weeks after BVS implantation. There are few publications reporting the early healing pattern after implantation of metallic scaffolds. ${ }^{20}$ At the OCT studies performed between 1 and 3 months after stenting, the reported $\%$ of uncovered stent struts was $0.1-10 \%$ with bare metal stents, $8.6-15 \%$ with sirolimus-eluting stents, $0.1-15 \%$ with zotarolimuseluting stents, $4.7-23 \%$ with EES and $14 \%$ with biolimus-eluting stents. ${ }^{20}$ Furthermore, the observed mean tissue (neointima) thickness of $0.09 \pm 0.02 \mathrm{~mm}$ in our study is comparable to the one reported 1-3 months after implantation of sirolimus- (0.03-
$0.04 \mathrm{~mm})$, zotarolimus- $(0.07-0.08 \mathrm{~mm})$, everolimus$(0.05-0.07 \mathrm{~mm})$, biolimus-eluting stents $(0.03 \mathrm{~mm})$, while thinner than after bare metal stent implantation $(0.35 \mathrm{~mm}){ }^{21-23}$ Thus, our data showing nearly complete scaffold coverage at the early phase after BVS implantation, makes lack of strut endothelialization as underlying mechanism for scaffold thrombosis, unlikely.

At follow-ups later than 6 months after implantation, there is evidence about comparable healing patterns between BVS and DES. ${ }^{9,10}$ In the randomized TROFI II study, at 6-month OCT examination, no differences regarding mean neointimal thickness and \% of uncovered struts was observed between both platforms in STEMI patients (BVS $0.11 \pm 0.03 \mathrm{~mm}$ and $0.5 \%$; EES $0.09 \pm 0.03 \mathrm{~mm}$ and $0.6 \%) .{ }^{10}$ Gomez-Lara and colleagues reported similar observation after treatment 


\section{EARLY VASCULAR HEALING AFTER BVS IMPLANTATION}

Table 2. Quantitative Coronary Angiography Measurements

\begin{tabular}{|c|c|c|c|c|}
\hline & All $(\mathrm{n}=26)$ & $\operatorname{ACS}(n=12)$ & $\mathrm{SA}(\mathrm{n}=14)$ & P-Value \\
\hline Vessel size (mm) & $2.57 \pm 0.4$ & $2.63 \pm 0.4$ & $2.51 \pm 0.5$ & 0.48 \\
\hline Stenosis length (mm) & $23.7 \pm 13.9$ & $23.6 \pm 15.5$ & $23.8 \pm 13.0$ & 0.98 \\
\hline \multicolumn{5}{|l|}{ Minimal lumen diameter (mm) } \\
\hline Before PCI & $0.87 \pm 0.5$ & $0.77 \pm 0.6$ & $0.95 \pm 0.4$ & 0.38 \\
\hline In-BVS after PCI & $2.36 \pm 0.4$ & $2.38 \pm 0.4$ & $2.33 \pm 0.4$ & 0.77 \\
\hline In-segment after PCI & $2.21 \pm 0.4$ & $2.36 \pm 0.5$ & $2.09 \pm 0.4$ & 0.14 \\
\hline In-BVS at re-angiogram & $2.30 \pm 0.4$ & $2.29 \pm 0.3$ & $2.31 \pm 0.5$ & 0.94 \\
\hline In-segment at re-angiogram & $2.17 \pm 0.5$ & $2.17 \pm 0.5$ & $2.16 \pm 0.4$ & 0.96 \\
\hline \multicolumn{5}{|l|}{$\%$ diameter stenosis } \\
\hline Before PCI & $66.2 \pm 17.6$ & $70.9 \pm 21.2$ & $62.2 \pm 13.5$ & 0.23 \\
\hline In-BVS after PCI & $9.7 \pm 7.4$ & $9.9 \pm 7.1$ & $9.6 \pm 7.9$ & 0.92 \\
\hline In-segment after PCI & $15.0 \pm 11.0$ & $11.1 \pm 8.9$ & $18.4 \pm 11.8$ & 0.09 \\
\hline In-BVS at re-angiogram & $10.2 \pm 7.1$ & $10.9 \pm 8.4$ & $9.6 \pm 6.2$ & 0.67 \\
\hline In-segment at re-angiogram & $15.5 \pm 13.9$ & $16.6 \pm 16.7$ & $14.6 \pm 11.6$ & 0.75 \\
\hline Acute lumen gain $(\mathrm{mm})$ & $1.49 \pm 0.6$ & $1.61 \pm 0.7$ & $1.38 \pm 0.5$ & 0.34 \\
\hline \multicolumn{5}{|l|}{ Lumen loss (mm) } \\
\hline In-BVS & $0.23 \pm 0.7$ & $0.28 \pm 0.8$ & $0.19 \pm 0.7$ & 0.76 \\
\hline In-segment & $0.19 \pm 0.8$ & $0.26 \pm 0.8$ & $0.15 \pm 0.8$ & 0.34 \\
\hline
\end{tabular}

Values are mean $\pm \mathrm{SD}$ or $\mathrm{n}(\%)$.

of patients presenting with stable or clinical unstable angina-at 1-year OCT examination mean neointimal thickness was $0.14 \pm 0.07 \mathrm{~mm}$ with BVS versus $0.12 \pm 0.05 \mathrm{~mm}$ with $\mathrm{EES}, \mathrm{P}=0.82$, while $\%$ uncovered struts was $4.5 \%$ with BVS and $5.3 \%$ with ESS. ${ }^{9}$
Differences in values observed between these two studies might derive from variety of measurement methodology used, from different time points of OCT examination but they might also suggest a diverse healing pattern of BVS in ACS and stable lesions. Data

Table 3. OCT Analysis at 6-8 Weeks Follow-Up

\begin{tabular}{|c|c|c|c|c|}
\hline & All $(\mathrm{n}=26)$ & $\operatorname{ACS}(n=12)$ & $\operatorname{SAP}(n=14)$ & P-Value \\
\hline Healing score & $3.6 \pm 5.6$ & $1.9 \pm 1.7$ & $5.3 \pm 7.3$ & 0.08 \\
\hline Minimal lumen diameter (mm) & $2.3 \pm 0.5$ & $2.3 \pm 0.4$ & $2.4 \pm 0.5$ & 0.57 \\
\hline Minimal lumen area $\left(\mathrm{mm}^{2}\right)$ & $4.5 \pm 1.7$ & $4.3 \pm 1.5$ & $4.7 \pm 1.9$ & 0.47 \\
\hline Mean lumen area $\left(\mathrm{mm}^{2}\right)$ & $5.8 \pm 2.0$ & $5.6 \pm 1.9$ & $5.9 \pm 2.1$ & 0.6 \\
\hline Minimal scaffold area $\left(\mathrm{mm}^{2}\right)$ & $5.3 \pm 1.8$ & $5.1 \pm 1.7$ & $5.4 \pm 2.0$ & 0.54 \\
\hline Mean scaffold area $\left(\mathrm{mm}^{2}\right)$ & $6.6 \pm 0.2$ & $6,8 \pm 2,2$ & $6,5 \pm 2,0$ & 0.63 \\
\hline Minimal scaffold diameter (mm) & $2.5 \pm 0.5$ & $2.5 \pm 0.4$ & $2.6 \pm 0.5$ & 0.62 \\
\hline Mean scaffold diameter (mm) & $2.9 \pm 0.5$ & $2.8 \pm 0.5$ & $2.9 \pm 0.5$ & 0.67 \\
\hline Minimal neointimal area $\left(\mathrm{mm}^{2}\right)$ & $0.4 \pm 0.1$ & $0.4 \pm 0.1$ & $0.4 \pm 0.1$ & 0.81 \\
\hline Mean neointimal area $\left(\mathrm{mm}^{2}\right)$ & $0.9 \pm 0.2$ & $0.9 \pm 0.2$ & $0.9 \pm 0.2$ & 0.71 \\
\hline \% Lumen diameter stenosis & $12.7 \pm 10.8$ & $13.1 \pm 9.5$ & $12.3 \pm 12.2$ & 0.83 \\
\hline$\%$ Lumen area stenosis & $23.2 \pm 19.3$ & $24.2 \pm 16.7$ & $22.3 \pm 22.0$ & 0.78 \\
\hline Mean tissue thickness/strut (mm) & $0.09 \pm 0.02$ & $0.09 \pm 0.02$ & $0.09 \pm 0.01$ & 0.86 \\
\hline Mean tissue thickness/cross-section (mm) & $0.18 \pm 0.06$ & $0.19 \pm 0.06$ & $0.17 \pm 0.06$ & 0.24 \\
\hline
\end{tabular}

Values are mean $\pm \mathrm{SD}$ or $\mathrm{n}(\%)$. 


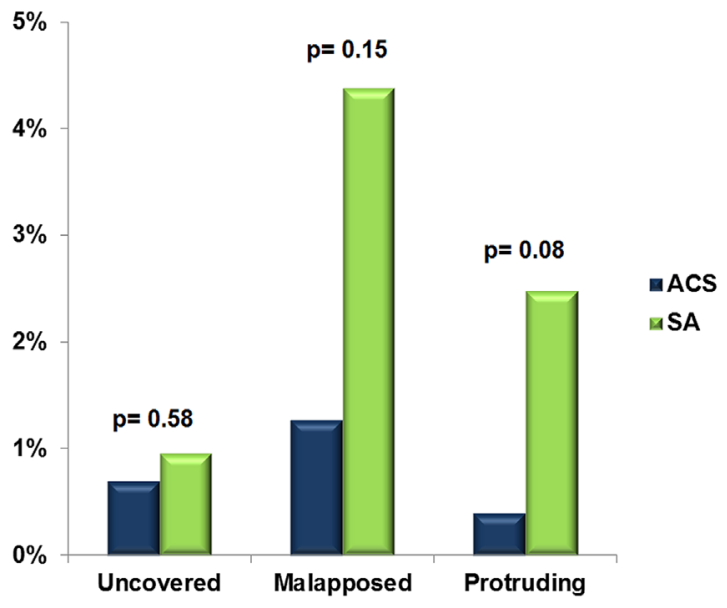

Figure 3. Results of qualitative OCT strut analysis. Percentages of uncovered, malapposed and protruding struts 47 days after BRS implantation in patients with ACS and SAP.

from histopathology and virtual histology intravascular ultrasound studies have shown that culprit lesions of ACS patients present more frequently as thin-cup fibro-atheromas, with greater amounts of necrotic core and smaller amounts of fibro-fatty plaque compared to target lesions in SA patients. ${ }^{24,25}$ Shaw et al. observed a correlation between the plaque composition and scaffold expansion and eccentricity immediately after BVS implantation. ${ }^{11}$ Particularly in calcific lesions a lower BVS expansion and greater eccentricity was observed highlighting the lower radial strength of the Absorb BVS compared to metallic scaffolds. ${ }^{18}$

In our study, neither in the amount of strut coverage nor in the $\%$ of uncovered scaffolds was a difference amongst ACS and SA patients. On the other hand, numerically higher $\%$ of protruding and malapposed struts was observed in SA patients compared to ACS patients, $1.26 \%$ versus $4.3 \%$ and $0.39 \%$ versus $2.48 \%$, respectively. Although in a recently published study, at 3-month after BVS implantation, reduced neointimal coverage and a higher proportion of uncovered struts in ACS patients compared to SAP patients was observed. ${ }^{26}$

The impact of clinical setting on comparative performance of BVS and DES has been not investigated and was beyond the aim of our study. Recent publications suggest however, a greater impact of procedural aspects on the increased risk of scaffold thrombosis compared to the clinical presentation at index PCI. ${ }^{6,27}$ The observed healing scores in ACS patients $(1.87 \pm 1.67)$ at 47 days after BVS implantation in our study are comparable with the ones reported by TROFI-II investigators 6 months after PCI with BVS $(1.74 \pm 2.39)$ and EES $(2.80 \pm 4.44$, Pnon-inferiority $<0.001)$ in STEMI patients. ${ }^{10}$ On the other hand, in a non-randomized comparison of BVS and EES healing patterns 1-year after implantation in patients presenting with stable or unstable angina, intraluminal masses were observed more frequently with BVS (in $12.9 \%$ of lesions) compared with EES ( $0 \%$ of lesions), supporting the worse healing score (5.28 \pm 7.28$)$ observed in our SA patients. ${ }^{9}$ Long-term presence of strut malapposition, protrusion or coronary evaginations has been reported after DES or BVS implantation, and might serve as possible mechanism for late stent thrombosis due to disturbances of laminar coronary flow. ${ }^{17,28-30}$ Our observations suggest an inferior mechanical performance of BVS in stable lesions despite similar amount and quality of scaffold tissue coverage among SA and ACS lesions.

\section{Limitations}

Although our study is the first report of a early BVS healing, acute and later in time OCT examinations were not performed. Furthermore, although there was a numerical difference in vascular healing parameters among SA and ACS patients, considering the limited sample size, the concept of better performance of BVS in ACS lesions compared to SA lesions remains hypothesis generating.

\section{Conclusion}

Independent of clinical presentation at the index percutaneous coronary intervention, at mean 47 days after BVS implantation complete tissue coverage of struts was observed. BVS treatment of ACS lesions seems to be associated with a better healing score compared to SA lesions. However, larger studies are required to support this hypothesis.

\footnotetext{
Acknowledgment: JM received lecture fees from Abbott Vascular, Terumo, Lilly/Daichii Sankyo, and Edwards Lifescience as well as received research grants through the hospital by Abbott Vascular and Edwards Lifescience. GG has a consultant agreement with Boston Scientific and St. Jude Medical and received research grants through the hospital by Abbott Vascular, Boston Scientific, and St. Jude Medical. The other authors have no conflicts of interest to declare.
} 


\section{EARLY VASCULAR HEALING AFTER BVS IMPLANTATION}

\section{References}

1. Puricel S, Arroyo D, Corpataux N, et al. Comparison of everolimus- and biolimus-eluting coronary stents with everolimus-eluting bioresorbable vascular scaffolds. J Am Coll Cardiol 2015;65:791-801.

2. Kimura T, Kozuma K, Tanabe K, et al. A randomized trial evaluating everolimus-eluting Absorb bioresorbable scaffolds vs. everolimus-eluting metallic stents in patients with coronary artery disease: ABSORB Japan. Eur Heart J 2015;36:33323342.

3. Ellis SG, Kereiakes DJ, Metzger DC, et al. Everolimus-eluting bioresorbable scaffolds for Coronary artery disease. N Engl J Med 2015;373:1905-1915.

4. Capodanno D, Gori T, Nef H, et al. Percutaneous coronary intervention with everolimus-eluting bioresorbable vascular scaffolds in routine clinical practice: Early and midterm outcomes from the European multicentre GHOST-EU registry. EuroIntervention 2015;10:1144-1153.

5. Puricel S, Cuculi F, Weissner M, et al. Bioresorbable Coronary scaffold thrombosis: Multicenter comprehensive analysis of clinical presentation, mechanisms, and predictors. J Am Coll Cardiol 2016;67:921-931.

6. Kolandaivelu K, Swaminathan R, Gibson WJ, et al. Stent thrombogenicity early in high-risk interventional settings is driven by stent design and deployment and protected by polymer-drug coatings. Circulation 2011;123:1400-1409.

7. Cassese S, Byrne RA, Ndrepepa G, et al. Everolimus-eluting bioresorbable vascular scaffolds versus everolimus-eluting metallic stents: A meta-analysis of randomised controlled trials. Lancet 2016;387:537-544.

8. Gomez-Lara J, Brugaletta S, Farooq V, et al. Head-to-head comparison of the neointimal response between metallic and bioresorbable everolimus-eluting scaffolds using optical coherence tomography. JACC Cardiovasc Interv 2011;4:12711280.

9. Sabaté M, Windecker S, Iniguez A, et al. Everolimus-eluting bioresorbable stent vs. durable polymer everolimus-eluting metallic stent in patients with ST-segment elevation myocardial infarction: Results of the randomized ABSORB ST-segment elevation myocardial infarction-TROFI II trial. Eur Heart J 2016;37:229-240.

10. Shaw E, Allahwala UK, Cockburn JA, et al. The effect of coronary artery plaque composition, morphology and burden on Absorb bioresorbable vascular scaffold expansion and eccentricity-A detailed analysis with optical coherence tomography. Int J Cardiol 2015;184:230-236.

11. Tearney GJ, Regar E, Akasaka T, et al. Consensus standards for acquisition, measurement, and reporting of intravascular optical coherence tomography studies: A report from the International Working Group for Intravascular Optical Coherence Tomography Standardization and Validation. J Am Coll Cardiol 2012;59: 1058-1072.

12. Nakatani S, Sotomi $\mathrm{Y}$, Ishibashi $\mathrm{Y}$, et al. Comparative analysis method of permanent metallic stents (XIENCE) and bioresorbable poly-L-lactic (PLLA) scaffolds (Absorb) on optical coherence tomography at baseline and follow-up. EuroIntervention 2015;11. pii: 20150528-02. [Epub ahead of print].

13. Räber L, Onuma $\mathrm{Y}$, Brugaletta $\mathrm{S}$, et al. Arterial healing following primary PCI using the Absorb everolimus-eluting bioresorbable vascular scaffold (Absorb BVS) versus the durable polymer everolimus-eluting metallic stent (XIENCE) in patients with acute ST-elevation myocardial infarction: Rationale and design of the randomised TROFI II study. EuroIntervention 2016;12:482-489.
14. Hoppmann P, Kufner S, Cassese S, et al. Angiographic and clinical outcomes of patients treated with everolimus-eluting bioresorbable stents in routine clinical practice: Results of the ISAR-ABSORB registry. Catheter Cardiovasc Interv 2016;87: 822-829.

15. Serruys PW, Chevalier B, Sotomi Y, et al. Comparison of an everolimus-eluting bioresorbable scaffold with an everolimuseluting metallic stent for the treatment of coronary artery stenosis (ABSORB II): A 3 year, randomised, controlled, single-blind, multicentre clinical trial. Lancet 2016; pii: S01406736(16)32050-5. [Epub ahead of print].

16. Guagliumi G, Sirbu V, Musumeci G, et al. Examination of the in vivo mechanisms of late drug-eluting stent thrombosis: Findings from optical coherence tomography and intravascular ultrasound imaging. JACC Cardiovasc Interv 2012;5:12-20.

17. Mattesini A, Secco GG, Dall'Ara G, et al. ABSORB biodegradable stents versus second-generation metal stents: A comparison study of 100 complex lesions treated under OCT guidance. JACC Cardiovasc Interv 2014;7:741-750.

18. Windecker S, Koskinas KC, Siontis GCM. Bioresorbable scaffolds versus metallic drug-Eluting stents: Are we getting any closer to a paradigm shift?. J Am Coll Cardiol 2015;66: 2310-2314.

19. Lee KS, Lee JZ, Hsu C-H., et al. Temporal trends in strut-Level optical coherence tomography evaluation of Coronary stent coverage: A systematic review and meta-Analysis. Catheter Cardiovasc Interv 2015. doi: 10.1002/ccd.26374. [Epub ahead of print].

20. Kim S-J., Lee H, Cho J-M., et al. Comparison of zotarolimuseluting stent and everolimus-eluting stent for vascular healing response: Serial 3-month and 12-month optical coherence tomography study. Coron Artery Dis 2013;24:431-439.

21. Kim B-K., Hong M-K., Shin D-H., et al. Optical coherence tomography analysis of strut coverage in biolimus- and sirolimus-eluting stents: 3-month and 12-month serial followup. Int J Cardiol 2013;168:4617-4623.

22. Xie Y, Takano M, Murakami D, et al. Comparison of neointimal coverage by optical coherence tomography of a sirolimuseluting stent versus a bare-metal stent three months after implantation. Am J Cardiol 2008;102:27-31.

23. Hong M-K, Mintz GS, Lee CW, et al. Comparison of virtual histology to intravascular ultrasound of culprit coronary lesions in acute coronary syndrome and target coronary lesions in stable angina pectoris. Am J Cardiol 2007;100:953-959.

24. Narula J, Nakano M, Virmani R, et al. Histopathologic characteristics of atherosclerotic coronary disease and implications of the findings for the invasive and noninvasive detection of vulnerable plaques. J Am Coll Cardiol 2013;61:1041-1051.

25. Giblett JP, Brown AJ, Keevil H, et al. Implantation of bioresorbable vascular scaffolds following acute coronary syndrome is associated with reduced early neointimal growth and strut coverage. EuroIntervention 2016;12:724-733.

26. Suwannasom P, Sotomi Y, Ishibashi Y, et al. The impact of post-Procedural asymmetry, expansion, and eccentricity of bioresorbable everolimus-Eluting scaffold and metallic everolimus-Eluting stent on clinical outcomes in the ABSORB II trial. JACC Cardiovasc Interv 2016;9:1231-1242.

27. Cook S, Wenaweser $\mathrm{P}$, Togni $\mathrm{M}$, et al. Incomplete stent apposition and very late stent thrombosis after drug-eluting stent implantation. Circulation 2007;115:2426-2434.

28. Gori T, Jansen T, Weissner M, et al. Coronary evaginations and peri-scaffold aneurysms following implantation of bioresorbable scaffolds: Incidence, outcome, and optical coherence tomography analysis of possible mechanisms. Eur Heart J 2015; ehv581. 